\title{
Nickel Based Nano Particles as Adsorbents in Water Purification Methods - A Review
}

\author{
K. RAVINDHRANATH* and MYLAVARAPU RAMAMOORTY \\ Department of Chemistry, K. L. University, Green Fields, Vaddeswaram - 522 502, \\ Guntur Dt., Andhra Pradesh, India. \\ ${ }^{*}$ Corresponding author E-mail: ravindhranath.kunta@gmail.com
}

http://dx.doi.org/10.13005/ojc/330403

(Received: May 18, 2017; Accepted: June 22, 2017)

\begin{abstract}
Nickel based nano particles are metallic $\mathrm{Ni}$ and $\mathrm{NiO}$. These materials find wide utility in various fields in view of their high surface potentials, surface area, semi conducting nature, reduction and complexing tendencies. The present review is mainly aimed at the investigations made in using these nano nickel particles as adsorbents in purifying water. The synthesis of nano particles of Ni/ $\mathrm{NiO}$ adopting the conventional physical/chemical methods, their draw backs and the progress so far made in the green synthesis of particles using plant extracts as reducing, capping and stabilizing argents, are also emphatically discussed. Further, the potential areas of research with respect to the green synthesis of the said nano particles and their applications to water purification are identified and comprehensively presented.
\end{abstract}

Keywords: review, nano particles, water treatment, phytomethods, Ni/NiO, adsorbents, pollutants.

\section{INTRODUCTION}

Nickel has two manifestations of nano particles: nickel metal and nickel oxide. These two classes of nano particles possess magnetic properties, biocompatibility, catalytic activity, antimicrobial activity and sorption nature. Further, nano-NiO is a semiconductor (band gap: 3.6 to $4.9 \mathrm{eV}$ ) with high chemical stability and electron transfer ability (Thema et al., 2016). Hence these nano particles are finding wide applications in diverse fields such as electronics, energy appliances (Karmhag $\mathrm{R}$ et al., 2000), biomedicines (Mariam A.A. et al., 2014), sensors, waste water treatment and in the various organic syntheses based on reduction, hydrogenation, alkylation etc (Li X.K et al., 2005, Saxena A et al., 2007, Alonso F et al., 2008, 2009 Dhakshinamoorthy A, 2008). Investigations are also being made in using these nano particles as adsorbents in water remediation methods as detailed hereunder.

The present review is a comprehensive account of the new research trends in green methods 
of synthesis of $\mathrm{Ni}$ and $\mathrm{NiO}$ nano particles and their applications to the wastewater treatment.

\section{Synthesis Of Nickel Based Nanoparticles By Physical / Chemical Routes}

Literature reports the synthesis of nickel nano particles using microwave assisted synthesis (Lai et al., 2006, Xu et al., 2008; Eluri and Paul, 2012), micro-emulsion synthesis (Ai et al., 2003; Chen and Wu, 2000; Khan, 2008), chemical reduction technique using suitable reducing agents like sodium borohydride (Hou et al., 2005), and hydrazine hydrate (Wu and Chen, 2003, Roselina and Azizan, 2012; Wu et al., 2012; Sudhasree et al., 2014), reversed micelles method (Harish et al., 2011), thermal decomposition of nickel (II) acetylacetonate in alkylamines (Chen et al., 2007) and sol-gel methods (Jia et al., 2008).

Various methods to fabricate $\mathrm{NiO}$ nano particles are reported in the literature which includes surfactant-mediated method (Wang et al., 2002), low-pressure spray pyrolysis (Lenggoro et al., 2003), precipitation-cum-calcination (Deng and Chen, 2004), simple liquid phase process (Wang et al., 2005), solvothermal method (Ghosh et al., 2006), chemical precipitation (Mahaleh et al., 2008), microwave-assisted hydrothermal method (Zhu et al., 2011), sol-gel method (Alagiri et al., 2012), thermal decomposition (Ghosh et al., 2006; Zhang et al., 2010) and other techniques (Cherrey et al., 2002; Tao and Wei, 2004; Wang and $\mathrm{Ke}, 1996)$.

Of all these methods, the sol-gel methods are simple and convenient. In these methods, the growth of nano particles are controlled by suitable choice of precursors, reducing agents and/or capping agents to stabilize the nano particles (Nowsath Rifaya et al., 2012, Pandey and Manivannan, 2015). The commonly used precursors are nickel chloride, nickel sulphate, nickel acetate, nickel nitrate, nickel carboxylate etc. and the reducing agents are sodium borohydride, sodium hydride, hydrazine hydrate, organic amine (oleyl amine), primary aliphatic amines (dodecylamine), sodium hypophosphite etc. and the capping agents are polyvinyl pyrrolidone (PVP), sodium dodecyl sulfate, cetyltrimethylammonium bromide (CTAB) and the organic solvents used are ether, unsaturated alkynes, ethylene glycol, diethylene glycol, triethylene glycol, polyethylene glycol, hexane, cyclohexane and octane etc (Nowsath Rifaya et al., 2012, Pandey and Manivannan, 2015). The reducing agents convert the nickel ions to nickel atoms and thus formed metal atoms are 'oozed out' from the aqueous or organic mother liquors in the atomic/molecular forms as they are insoluble. Then they start growing by aggregation called Ostwald ripening, and when they come to the nano-size, the capping agents have to arrest the further growth or otherwise, the particles pass through the colloidal stage and precipitate (Sun, Y.P et al., 2007, Pandian, C. J. et al., 2015). Here, the success or failure of the synthesis depends upon the growth conditions and much based on adopting the theoretical principles of crystal growth using homogeneous precipitations whether it is in aqueous or organic media (Vogel, 1989, Ling Bing Kong et al., 2015). When metal oxide nano particles are to be prepared, in place of reducing agents, precipitating agents are needed for precipitating the metal ions as hydroxides and/or hydrated oxide under controlled conditions besides the usual capping and stabilizing agents.

\section{Applications Of Nickel Based Nanoparticles Anti microbial activity}

The microbial activities of nano particles are attributed to their shape and size, surface area, chemical nature and functional groups present on the solution-solid interface and photo-sensitivity. Antibacterial activity of nickel nanoparticles against E. coli, L. cassie, S. aureus, P. aerugenosa and B. subtilis are studied by Chevellier, 1996. Nickel nanoparticles synthesized from leaf extract of Ocimum sanctum are shown good antimicrobial activity against pathogenic Gram-negative (E. coli, K. pneumoniae, and S. typhi), Gram-positive (B. subtilis, $S$. epidermidis) bacteria and fungi (C. albicans, $C$. tropicalis, A. fumigatus, A. clavatus, and $A$. niger) (Pandian et al., 2015). Antimicrobial activities of nickel and nickel oxides nanoparticles are reported against urinary tract infectious bacterial pathogens by Ravikumar et al., 2012.

Antibacterial activity of Nickel $(\mathrm{Ni})$ and bimetallic $\mathrm{Cu}-\mathrm{Ni}$ nanoparticles are tested against the human pathogens: Staphylococcus aureus (gram-negative) and Escherichia coli (gram-positive) (Pang et al., 2009; Kumar et al., 2010; Liliana et al., 2014). Ratiram G C et al., 2015 synthesized 
nano Ni using Nickel nitrate as precursor, hydrazine hydrate as reducing agent and ehtylenediamine as capping agent and the nano particles so obtained are probed for their antibacterial activities against human bacterial pathogens such as Klebsiella sp, Staphylococcus aureus, Enterococcus faecalis, Escherichia coli, and Pseudomonas aeruginosa by using well diffusion method.

Khashan et al., 2016 synthesized colloidal $\mathrm{NiO}$ nanoparticles and their antimicrobial activity was investigated against pseudomonas aurogenisa, Escherichia coli, Staphylococcus aureus and Streptococcus pneumonia.

\section{Mechanism of antimicrobial activity:}

By virtue of high surface area and redox potential $\left(\mathrm{Ni}^{2+} / \mathrm{Ni}\right)-0.14 \mathrm{~V}$, the surface $\mathrm{Ni}$ atoms on nano Ni particles get oxidized to $\mathrm{Ni}^{2+}$ with the release of highly reactive oxygen species (ROS) when the nano particles are in contact with water. The ROS passes through the cell membranes and denature the proteins and subsequently results in cellular content leakage. $\mathrm{Ni}^{2+}$ and/or free radicals prevent or block the transport of electrons in the microbial cell and thereby cause the cell death (Pandian et al., 2015). Similar observations are reported with nano particles of $\mathrm{Ag}$ with regard to their antimicrobial nature (Mallikarjuna et al., 2011; Kenneth et al., 2010).

\section{Removal of pollutants}

The nano particles of $\mathrm{Ni}$ or $\mathrm{NiO}$ are less investigated in the treatment of waste waters, in contrast to the large literature available pertaining to their applications in other fields of research viz., catalytic, anti-microbial, bio-medical, Electrochemical, sensor etc.

Nickel oxide is considered as good adsorbent due to its chemical and magnetic properties (Roya et al., 2012, 2013). Uzaira Rafique et al., (2012) synthesized nano NiO using co-precipitation method and the obtained particles were probed for their adsorption nature towards Sulphate and Nitrate. It was noted that the adsorbent was effective at $\mathrm{pH}: 7$ for the removal of both anions from waters.
Srivastava N K et al., 2014 prepared nano $\mathrm{NiO}$ using Nickel acetate as precursor. To the ethanolic solution of precursor, oxalic acid solution was added to obtain a green gel. Then the gel was dried, grounded and calcinated at elevated temperature between $300^{\circ} \mathrm{C}$ to $700^{\circ} \mathrm{C}$ to obtain the nano particles. Thus synthesized nano $\mathrm{NiO}$ was investigated for its sorption nature with respect to various physicochemical parameters such as $\mathrm{pH}$, sorbent dosage, agitation time, initial Conc. of Chromium ion. The adsorbent was found to be effective.

Fereshteh Motahari et al, 2015, hydrothermally synthesized $\beta-\mathrm{Ni}(\mathrm{OH})_{2}$ using Nickel nitrate and sodium hydroxide as precursors and $\mathrm{H}_{2}$ acacen as stabilizer. Then $\beta-\mathrm{Ni}(\mathrm{OH})_{2}$ was subsequently calcinated to obtain nano $\mathrm{NiO}$. The effectiveness of so prepared nano $\mathrm{NiO}$ in the removal of dye Rhodamine B from polluted waters was investigated and found to be successful.

Amira M et al., 2015 studied the extraction of $\mathrm{Pb}^{2+}$ from waters using nano $\mathrm{Ni}$ as adsorbent. The nano $\mathrm{Ni}$ was prepared adopting two different routes. In one, aqueous solution of $\mathrm{NaOH}$ was added to the Nickel Nitrate solution and the precipitate of $\mathrm{Ni}(\mathrm{OH})_{2}$ obtained was filtered, washed, dried and calcinated at $400{ }^{\circ} \mathrm{C}$. In the other route, an ethanolic solution of Oxalic acid was added to the ethanolic solution of Nickel Nitrate and the resulting precipitate was filtered, washed with ethanol and acetone, dried and calcinated at $400^{\circ} \mathrm{C}$. It was found that the nano $\mathrm{Ni}$ prepared in the second route was found to be more effective in the removal of potential pollutant, $\mathrm{Pb}^{2+}$ from polluted waters.

Mingyi Tang et al., 2014, by using nano $\mathrm{Ni}$ particles loaded poly(acrylamide-co-acryl acid) as a catalyst, studied the removal of potential organic pollutant, 4-nitrophenol, with $\mathrm{NaBH}_{4}$ a reducing agent. Roya Nateghi et al., 2012 investigated the removal of mono azo Orange II dye from waste waters using commercially available nano $\mathrm{NiO}$ as adsorbent and found to be effective. The surface of the adsorbent diatomite was modified with nano $\mathrm{NiO}$ oxide and was used in the extraction of basic red 46 (Khalighi et al., 2012). Under optimum extraction 
conditions, the adsorption capacity was found to be $105.61 \mathrm{mg} / \mathrm{g}$ (pH:7; temp. $25 \pm 1{ }^{\circ} \mathrm{C}$, equilibration time: $1 \mathrm{hr}$; 200 rpm; initial conc. of dye: 25 ppm).

\section{Other Uses}

The nickel based nano particles have wide applications in view of their catalytic, magnetic and semi conducting nature. They are used as electrodes in solid oxide fuel cells, catalysts in various industrial syntheses, coloring agents for enamels and paints and in making nano wires and fibers. As these materials are magnetic in nature, they are used in making permanent magnets, magnetic fluids, magnetic recording media, and electronic parts. They are also used in plastic and textile industries and in making adhesive formulations and further, they are used in making lightweight aerospace components and also as gas sensors (Chen and Hsieh, 2002; Kurihara et al., 1995; Dooley et al., 1994; Biji and Khadar, 2001; Kodama, 1999; Li F et al., 2002; Matsumiya et al., 2002).

\section{Green Synthesis And Applications To Water Treatment:}

All the above said chemical and physical methods used in the synthesis of nickel based nanoparticles are costly, involve complicated procedures and cause environmental pollution besides low productivity (Nagaraj et al., 2011). The nano particles produced by these methods have less biocompatibility and less antioxidant and microbial activities besides high cytotoxic nature. Hence, researchers are trying to develop green methods based bio-materials especially with the plant extracts (Abdul-Raheim M et al, 2016, Shakeel Ahmed et al., 2016; Palaniselvam Kuppusamy et al., 2016).

Hence, eco-friendly synthetic methods based on biomaterials like plant extracts and microbes are interesting the researchers in developing simple, economical and effective methodologies for the simple fact that the plants are the limit-less sources of diverse chemical compounds which can serve as reducing, capping and stabilizing agents. The chemical compounds such as vitamins, sugar, proteins, peptides, polyphenols etc., that present in flora materials may serve this purpose by virtue of possessing different functional groups such as $-\mathrm{OH}$, $-\mathrm{HCHO},-\mathrm{COOH}, \mathrm{C}=\mathrm{O}$, esters, amino, amide groups etc. that can be oxidized or reduced or involved in the complex formation with the surface functional groups of the nano Ni/NiO particles (Kowshik et al., 2003; Singh et al., 2005; Nadagouda and Varma, 2006; Raveendran et al., 2006; Raj and Viswanathan, 2011).

This mode of research is interesting the researchers as the nano particles thus synthesized are bio-compatible and eco-friendly and in the event of their contamination in the water bodies, they are unlikely to be hazardous (Vaseem et al., 2013, Paskalis Sahaya et al., 2014, Amira M. Mahmoud, 2015).

\section{Synthesis of Nickel (Ni) nanoparticles using plants}

The nano Ni particles are easily oxidizable and to make them stable in aqueous solutions, capping agents are used. The conventional synthetic capping agents are toxic. Hence, researchers are looking towards plants whose bio-extracts contain compounds that can serve as reducing agents as well as capping agents viz. sugars, vitamins., polyphenols etc. Only few reports are available in this aspect of synthesis.

Chen et al., 2014, used the extracts of Medicago sativa (alfalfa) for the synthesis of $\mathrm{Ni}$ nano particles. The precursor used was $\mathrm{Ni}\left(\mathrm{NO}_{3}\right)_{2}$ and the reduction was carried out at room temperature and the obtained particles were freeze-dried for one day to obtain nano particles of Ni. Vaseem et al, 2013, found that glucose served both as reducing and capping agent, when Nickel salt solution was treated with glucose and ammonia. The aldehyde group in the glucose causes the reduction of $\mathrm{Ni}^{2+}$ to $\mathrm{Ni}$ and in doing so, it is oxidized to carboxylate group. Thus obtained caroxylate groups and hydroxyl groups in the glucose, are bound to the the surface of Ni nano particles and thereby, prevent the aggregation of $\mathrm{Ni}$ particles i.e. the nano particles are capped.

Dutta and Dolui, 2011, synthesized nano Ni using naturally occurring tanic acid as reducing and stabilizing agent. Mariam et al., (2014) used leaves extract of Azadirachta indica for the synthesis. Abhijit Kar and Ajoy Kumar Ray, 2014, on pyralysis of the petals of Hibiscus rosa-sinensis soaked in Nickel chloride solution obtained 10 to $200 \mathrm{~nm}$ sized nano $\mathrm{Ni}$ 
particles. These particles were found to have carbon on their surface which prevented the agglomeration and responsible for stability of particles.

Muhmmad Imran Den and Aneela Rani, 2016, reviewed the literature available on chemical and green methods of synthesis of $\mathrm{Ni}$ and $\mathrm{NiO}$ nano particles and the influence of the method of preparation on the physicochemical properties of the said nano particles. Alfalfa plant extract (Huimei et al., 2014), Desmodium gangeticum root extract (Sudhasree et al., 2014), root tuber extract of Dioscorea (Elephant Yam) (Helen and Rani , 2015) and leaf extract of Coriander (Vasudeo and Pramod, 2016) were also used for the synthesis of nano $\mathrm{Ni}$.

Angajala et al., 2014, used leaf extract of Aegle marmelos Correa $(\mathrm{AmC})$ as a reducing and capping agent and $\mathrm{NiCl}_{2} 6 \mathrm{H}_{2} \mathrm{O}$ as precursor in synthesizing nano $\mathrm{Ni}$. It was observed that Sitosterol, naturally present in the leaves extract of sterol plant, was bound to the nano particles through its -OH groups and thereby imparting its antiinflammatory properties to the nanoparticles. Using $\mathrm{NiO}$ as precursor and the Annona squamosa leaves extract as reducing and capping agent, Mamuru et al., 2015, synthesized nano $\mathrm{Ni}$ at $\mathrm{pH}: 7$.

\section{Synthesis of nickel oxide (NiO) nanoparticles using plants}

Mariam et al., (2014) synthesized $\mathrm{NiO}_{2}$ and Ni nanoparticles using leaf extracts of Psidium guajava and Azadirachta indica respectively. Rambutan peel waste was found to serve as capping and stabilizing agent in the synthesis of $\mathrm{NiO}$ nanocrystals using Nickle sulphate as precursor (Yuvakkumar et al., 2014). Thema et al., 2016 synthesized nano $\mathrm{NiO}$ with Agathosma betulina natural extract.

Some investigations were made using microbes viz., bacteria, yeast, fungi, as reducing and/or stabilizing agents in the preparation of $\mathrm{NiO}$ nano particles. Salvadori et al., 2014 used dead biomass of filamentous fungus while Ullah et al, 2014 used Rhizopus nigricans fungus. Using the bacteria, Microbacterium sp. MRS-1, Sathyavathi et al, 2014 synthesized $\mathrm{NiO}$ nano particles.
All these particles prepared from these biomeans are found to have biocompatibility because the capping, reducing and stabilizing agents are derived from biomaterials such as sugars and flavonoids which are not cytotoxic.

\section{Removal of dyes and pollutants using green synthesized nano $\mathrm{Ni} / \mathrm{NiO}$}

Pandian C J et al., 2015 synthesized Ni nanoparticles by treating $\mathrm{Ni}\left(\mathrm{NO}_{3}\right)_{2}$, solution with the leaves extract of Ocimum sanctum at $60^{\circ} \mathrm{C}$ and the resulting particles were freeze dried for one day. Thus obtained particles were used as adsorbent in the removal of dyes viz., eosin, crystal violet and orange II and also anions, $\mathrm{NO}_{3}^{-}$and $\mathrm{SO}_{4}{ }^{2-}$ from polluted water and found to be effective.

\section{Comparison with Other Similar Inorganic Materials}

Of the $\mathrm{Ti}, \mathrm{Al}, \mathrm{Fe}, \mathrm{Ni}$-based nano materials, it is evident that as nano $\mathrm{Al}$ is highly reactive and thermodynamically unstable when in contact with water or air due to its high reduction potentials, $\mathrm{E}^{\circ}=-1.677 \mathrm{~V}$ and hence, only the stable $\mathrm{Al}_{2} \mathrm{O}_{3}$ in different manifestations, are probed as adsorbents in water purification methods. The nano particles of $\mathrm{Fe}$ and $\mathrm{Ni}$ are less reactive compared to $\mathrm{Al}$ as their standard reduction potentials are: $E^{\circ}=-0.440$ and $-0.236 \mathrm{~V}$ respectively, and further, $\mathrm{Ni}$ exhibits passivity for oxidation. Hence, researchers are employing zero valent nano particles as well as their oxides of $\mathrm{Fe}$ and $\mathrm{Ni}$ as adsorbents in developing the water treatment methods. Iron oxide or its oxyhydroxide have many forms viz., $\mathrm{Fe}_{3} \mathrm{O}_{4}, \alpha-\mathrm{Fe}_{2} \mathrm{O}_{3}, \gamma-\mathrm{Fe}_{2} \mathrm{O}_{4}$ and $\mathrm{FeOOH}$ while Ni has only one oxide $\mathrm{NiO}$. This is because of more oxidizable tendency of Iron than Nickel and is attributed to the formation of continuous and protective oxide film on $\mathrm{Ni}$ surface resulting the passive nature to the $\mathrm{Ni}$ and in fact, $\mathrm{Ni}$ is used as protective coating for steals. These oxide forms are endowed with strong adsorption forces of diverse nature i.e. electrostatic interactions, ion exchanging and ion-association tendencies, complex formations etc. and these are of immense use in evoking affinity between the pollutants and surface of the adsorbent, which results in the successful extraction of pollutants from wastewaters. In this aspect, iron oxide based 
adsorbents are extensively being probed in view of their diverse nature than Nickel oxide adsorbent, $\mathrm{NiO}$ and further, the iron based materials are cheap and bio-degradable. Some investigations are also devoted to control the oxidation tendencies of the nano particles of $\mathrm{Fe}$ and $\mathrm{Ni}$ by alloying them with another stable metal or by entrapping in the matrix of some templates or polymer (synthetic or natural). These zero valent $\mathrm{Fe}$ and $\mathrm{Ni}$ are used as catalysts in the oxidation of oxidizable organic and inorganic impurities in wastewaters.

Coming to $\mathrm{Ti}$, the most stable state is +4 and compounds with $-1,0,+2$ and +3 are easily converted to the tetravalent state when the compounds are in contract with air, water or in presence of oxidation environment (Lee J D, 2010). Hence, methodologies of water treatment are confined to $\mathrm{TiO}_{2}$, a versatile adsorbent.

Thus the nano particles of $\mathrm{Al}, \mathrm{Ti}, \mathrm{Fe}$ and $\mathrm{Ni}$-based materials that are used as adsorbents in water/waste water treatments, comprise of : $\mathrm{Al}_{2} \mathrm{O}_{3} ; \mathrm{TiO}_{2}$, zero-valent $\mathrm{Fe}$ and its various oxides/ oxyhydroxides, zero-valent $\mathrm{Ni}$ and its only oxide: $\mathrm{NiO}$. These materials are being investigated with respect to green methods of syntheses and their water remediation methods as the nano particles derived by using plant extracts has a changed surface morphology than the conventionally prepared nano particles and it is attributed to the adsorption of some bio-compactable compounds present in the natural extracts (Vaseem et al., 2013). One investigation made by Abhijit Kar and Ajoy Kumar Ray, 2014, using petals of Hibiscus rosa-sinensis plant as 'template' is interesting to quote here. In this investigation, the advantage of the naturally existing minute pores in the petals is exploited in synthesizing uniform-nano Ni. These novel concepts are to be investigated in conjunction with water treatment methods in exploring or indentifying such hidden advantages bestowed on us by the nature. The surface characteristics of nano materials based on inorganic materials can be tailor-made to our specific needs and requirements in adsorptive removal of pollutants from waters.

\section{Conclusions And Future Perspectives}

The review reflects that the investigations pertaining to the plant and microbial mediated routes of synthesizing nano particles of $\mathrm{Ni}$ and $\mathrm{NiO}$ are limited. The particles synthesized by these routes are endowed with biocompatibility, stability and enhanced sorption nature. Further, only few investigations are reported using these nano particles as adsorbents in wastewater treatment.

The following are the identified areas of research:

\section{Synthesis of Nano $\mathrm{Ni}$ and $\mathrm{NiO}$}

Plant extracts containing compounds that serve as reducing and capping agents in stabilizing the nano particles of $\mathrm{Ni}$ and $\mathrm{NiO}$ are to be identified in the available flora.

Plant materials having uniform micropores may serves as template or substrate and they may help in the production of the same size nano particles of $\mathrm{Ni} / \mathrm{NiO}$, as has been investigated by Abhijit Kar and Ajoy Kumar Ray (2014), with regard to the synthesis of nano $\mathrm{Ni}$ using Hibiscus flower petals as biotemplate.

By suitably tailor making the conditions of synthesis, isotropic/ anisotropic $\mathrm{Ni} / \mathrm{NiO}$ nano particles of definite shape and size can be fabricated and thereby, enhancing surface potentials which may be exploited for binding the pollutants to the surface.

- Microbial mediated synthesis of nano $\mathrm{Ni}$ and $\mathrm{NiO}$ are less investigated and this is another vital aspect for research

Surface morphological studies are to be undertaken in understanding the mechanisms of formation of nano particles of $\mathrm{Ni} / \mathrm{NiO}$.

\section{Nano $\mathrm{Ni} / \mathrm{NiO}$ as adsorbent in Wastewater treatment}

- $\quad$ Nano $\mathrm{Ni}$ exhibits sorption nature mainly via reduction (redox potential for $\mathrm{Ni}^{2+} / \mathrm{Ni}$ is $-0.24 \mathrm{~V}$ ) while nano $\mathrm{NiO}$ via complex formation. There are only few reports available in literature pertaining to the removal of some dyes, organic pollutants, $\mathrm{Pb}^{2+}$, Chromate, Nitrate and Sulphates as has been reviewed above. It is quite surprising. Hence methodologies are to be developed in the purification of waste waters especially for the removal of toxic 
cations and anions and organic pollutants using bio-synthesized nano particles because the surface of the bio-synthesized particles are supposed to be energized for conducive sorption via complex formation or reduction or both.

- $\quad$ By doping the nano-oxides with rare earth elements, the catalytic activity for the reduction or oxidation of organic pollutants in wastewaters may be enhanced. This is a significant aspect of pollution-control research.

- Nano-particles when used as compact beds in continuous extraction methods, cause great pressure head loss. This can be avoided by using open columns or films or beads or pellets doped with the nano particles of $\mathrm{Ni} / \mathrm{NiO}$. Thus by immobilizing the nano particles of $\mathrm{Ni} / \mathrm{NiO}$ on a certain polymeric subtract (synthetic or natural), the sorption potentialities of nano particles can be explored without compromising for the slow rate of filtration and thereby the pollutants can be effectively removed. These studies need to be explored. Further, regeneration studies of the active surface of the adsorbent after exhausted are to be investigated.

\section{REFERENCES}

1. Abdul-Raheim M. Abdul-Raheim, El-Saeed Shimaa M., Farag Reem K., Abdel-Raouf Manar E, "Low cost biosorbents based on modified staqrch iron oxide nano composites for selective removal of some heavy metals from aueous solutions,",Adv. Mater. Lett., 2016, 7(5), 402-409.

2. Abhijit Kar, Ajoy Kumar Ray, "Synthesis of nano-spherical nickel by templating hibiscus flower petals," Journal of Nanoscience and Nanotechnology, 2014, 2(2), 17-20.

3. Ai, D., Kang, S., Dai, X. and Kwong, $H$. "Synthesis of nickel nanoparticles in microemulsion," China Particuology, 2003, 1, 131.

4. Alagiri, M., Ponnusamy, S. and Muthamizhchelvan, C., "Synthesis and characterization of $\mathrm{NiO}$ nanoparticles by solgel method," Journal of Materials Science: Materials in Electronics, 2012, 23(ㅈ) , 728732.

5. Alonso F, P. Riente, and M. Yus, "Wittig-type olefination of alcohols promoted by nickel nanoparticles: synthesis of polymethoxylated and polyhydroxylated stilbenes," European Journal of Organic Chemistry, 2009, 34, 6034-6042.

6. Alonso F. , P. Riente, and M. Yus, "Alcohols for the $\alpha$-alkylation of methyl ketones and indirect aza-wittig reaction promoted by nickel nanoparticles," European Journal of Organic Chemistry, 2008, 2008(29), 4908-4914.

7. Alonso F., P. Riente, and M. Yus,
"Hydrogen-transfer reduction of carbonyl compounds promoted by nickel nanoparticles," Tetrahedron, 2008 , 64(8),1847-1852.

8. Amira M. Mahmoud, Fatma A. Ibrahim , Seham A. Shaban, Nadia A. Youssef, "Adsorption of heavy metal ion from aqueous solution by nickel oxide nano catalyst prepared by different methods," Egyptian Journal of Petroleum,2015, 24, 27-35.

9. Angajala, G. and Radhakrishnan, S., "A review on nickel nanoparticles as effective therapeutic agents for inflammation," Inflammation and Cell Signaling, 2014 , 1(3), 1-8.

10. Biji, V. and Khadar, M.A., "Analysis of AC electrical properties of nanocrystalline nickel oxide," Mater. Sci. Eng. A,2001, 304, 814817.

11. Chen, D. and Hsieh, C., "Synthesis of nickel nanoparticles in aqueous cationic surfactant solutions," J Mater Chem.,2002, 12, 2412-5.

12. Chen, D.H. and Wu, S.H., "Synthesis of nickel nanoparticles in water-in-oil microemulsions," Chemistry of Materials, 2000, 12(5), 13541360.

13. Chen, H., Wang, J., Huang, D. et al., "Plantmediated synthesis of size-controllable $\mathrm{Ni}$ nanoparticles with alfalfa extract," Materials Letters, 2014, 122, 166-169.

14. Chen, Y.Z., Peng, D.L., Lin, D.P., Luo, X.H., "Preparation and magnetic properties of nickel nanoparticles via the thermal decomposition of nickel organometallic 
precursor in alkylamines," Nanotechnology, 2007, 18(50),

15. Cherrey, S.I., Tillement, O., Dubois, J.M., Massicot, F., Fort, Y., Ghanbaja, J., Colin, S.B., "Synthesis and characterization of nano-sized nickel(II), copper(I) and zinc(II) oxide nanoparticles, Mater. Sci. Eng. A, 2002, 338(1-2), 70-75.

16. Chevellier, A., "The Encylopedia of Medical Plant. London. Dorling Kindersley Ltd." (online). http:// www.chclibrary.org/plant. html.1996.

17. Deng, X. and Chen, Z., "Preparation of nano$\mathrm{NiO}$ by ammonia precipitation and reaction in solution and competitive balance," Materials Letters, 2004, 58(3-4), 276-280.

18. Dhakshinamoorthy A. and K. Pitchumani, "Clay entrapped nickel nanoparticles as efficient and recyclable catalysts for hydrogenation of olefins," Tetrahedron Letters, 2008, 49(11), 1818-1823.

19. Dooley, K.M., Chen, S.Y. and Ross, J.R.H., "Stable Nickel-Containing Catalysts for the Oxidative Coupling of Methane," J. Catal., 1994, 145(2), 402-408.

20. Dutta, A. and Dolui, S. K., "Tannic acid assisted one step synthesis route for stable colloidal dispersion of nickel nanostructures," Applied Surface Science, 2011, 257(15), 68896896.

21. Eluri, R. and Paul, B., "Microwave assisted greener synthesis of nickel nanoparticles using sodium hypophosphite," Materials Letters, 2012,76, 36-39.

22. Fereshteh Motahari, Mohammad Reza Mozdianfard, Masoud Salavati-Niasari, "Synthesis and adsorption studies of $\mathrm{NiO}$ nanoparticles in the presence of $\mathrm{H}_{2}$ acacen ligand, for removing Rhodamine $B$ in wastewater treatment", Process Safety and Environmental Protection,2015, 93, 282-292

23. Ghosh, M., Biswas, K., Sundaresan, A. and Rao, C. N. R., "MnO and $\mathrm{NiO}$ nanoparticles: synthesis and magnetic properties," Journal of Materials Chemistry, 2006, 16(1), 106-111.

24. Harish, K., Renu, R. and Kumar, S.S., "Synthesis of Nickel Hydroxide Nanoparticles by Reverse Micelle Method and Its Antimicrobial Activity," Research J. of Chemical Sci., 2011,1, 4248.
25. Helen, S.M. and Rani, M.H.E., "Characterization and antimicrobial study of nickel nanoparticles synthesized from dioscorea (Elephant Yam) by green route," International Journal of Science and Research,2015, 4(11), 216-219.

26. Hou, Y., Kondoh, H., Ohta, T. and Gao, S., "Size controlled synthesis of nickel nanoparticles," Applied Surface Science, 2005, 241, 218.

27. Huimei, C., Jing, W., Dengpo, H., Xiaoer, C., Jiajia, Z., Daohua, S., Jiale, H., Qingbiao, L., "Plant-mediated synthesis of size-controllable Ni nanoparticles with alfalfa extract," Mat Lett.,2014, 122, 166-69.

28. Jia, F., Zhang, L., Shang, X. and Yang, Y., "Non-aqueous sol gel approach towards the controllable synthesis of nickel nanospheres, nanowires, and nanoflowers," Advanced Materials,2008, 20(5), 1050-1054.

29. Karmhag R, T. Tesfamichael, E. Wäckelgård, G. A. Niklasson, and M. Nygren, "Oxidation kinetics of nickel particles: comparison between free particles and particles in an oxide matrix," Solar Energy, 2000, 68(4), 329-333.

30. Kenneth, K., Wong, Y. and Xuelai, L., "Silver nanoparticles-the real silver bullet in clinical medicine," Medicinal Chemistry Communications, 2010, 1, 125-131.

31. Khalighi, S.R., Khosravi, M.R., Badii, K.H., Yousefi, L., "Adsorption of Acid Blue 92 dye on modified diatomite by Nickel oxide nanoparticles in aqueous solution," Prog. Color. Colorants Coat., 2012, 5, 101-116.

32. Khan, A., "Preparation and characterization of magnetic nanoparticles embeded in microgels," Materials, 2008, 62, 898.

33. Khashan, K.S., Sulaiman, G.M., Abdul Ameer, F.A. and Napolitano, G., "Synthesis, characterization and antibacterial activity of colloidal NiO nanoparticles" Pak J Pharm Sci., 2016, 29(2), 541-546.

34. Kodama, R.H., "Magnetic nanoparticles," J. Magn. Magn. Mater., 1999, 200(1-3), 359372.

35. Kowshik, M., Ashtaputre, S., Kharrazi, S. et al., "Extracellular synthesis of silver nanoparticles by a silver-tolerant yeast strain MKY3," Nanotechnology, 2003, 14(1), 95100.

36. Kumar B, R.K. Thareja, "Synthesis of 
nanoparticles in laser ablation of aluminum in liquid," J. Appl. Phys. 2010,108, 064906.

37. Kurihara, L.K., Chow, G.M. and Schoen, P.E., Nanostructure Mater., 1995, 5, 607.

38. Lai, T.L., Hong, Y.Y., Gau, G.Y., Shu, Y.Y., Wang, C.B., "Microwave-enhanced catalytic degradation of phenol over nickel oxide," Appl. Catal. B, 2006, 68(3-4), 147-153.

39. Lee J D, Concise Inorganic Chemistry, Fifth Edition, Wiley- India, 2010

40. Lenggoro, I.W., Itoh, Y., lida, N., Okuyama, K., "Control of size and morphology in $\mathrm{NiO}$ particles prepared by a low-pressure spray pyrolysis," Mate decomposition over Ru and Ni catalysts supported on fumed $\mathrm{SiO}_{2}, \mathrm{MCM}$ 41, and SBA-15," Journal of Catalysis, 2005, 236(2), 181-189.

42. Li, F., Chen, H., Wang, C. and Hu, K., "A novel modified $\mathrm{NiO}$ cathode for molten carbonate fuel cells," J. Electroanal. Chem., 2002, 531(1), 53-60.

43. Liliana, A.F., Raul, A.M.L., Rogelio, J.S.V. and Oscar, F. O. M., "Synthesis, characterization and antibacterial activity of copper, nickel and bimetallic $\mathrm{Cu}-\mathrm{Ni}$ nanoparticles for potential use in dental materials," Progress in Natural Sci.: Materials Int., 2014 , 24, 321-328.

44 Ling Bing Kong, Y. Z. Huang, W. X. Que, T. S. Zhang, S. Li, J. Zhang, Z. L. Dong, D. Y. Tang, Tranp, Transparent Ceramics, 2015, Springers

45. Mahaleh, Y., Sadrnezhaad, S. K. and Hosseini, D., "NiOnanoparticles synthesis by chemical precipitation and effect of applied surfactant on distribution of particle size," Journal of Nanomaterials, 2008.

46. Mallikarjuna, K., Narasimha, G., Dillip, G. R. et al., "Green synthesis of silver nanoparticles using Ocimum leaf extract and their characterization," Digest Journal of Nanomaterials and Biostructures, 2011, 6(1), 181-186.

47. Mamuru, S. A., Bello, A. S. and Hamman, S. B., "Annona squamosa leaf extract as an efficient bioreducing agent in the synthesis of chromium and nickel nanoparticles," International Journal of Applied Sciences and Biotechnology, 2015, 3(2), 167-169.

48. Mariam A. A. , M. Kashif, S. Arokiyaraj et al., "Bio-synthesis of $\mathrm{NiO}$ and $\mathrm{Ni}$ nanoparticles and their characterization," Digest Journal of Nanomaterials and Biostructures, 2014, 9(3), 1007-1019.

49. Matsumiya, M., Qiu, F., Shin, W., Izu, N., Murayama, N. and Kanzaki, S., "Thin-film Lidoped $\mathrm{NiO}$ for thermoelectric hydrogen gas sensor," Thin Solid Films, 2002, 419(1-2), 213-217.

50. Mingyi Tang, Guanbo Huang, Sai Zhang , Yue Liu , Xianxian Li , Xingrui Wang ,Xiaobo Pang Haixia Qiu, "Low-cost removal of organic pollutants with nickel nanoparticle loaded ordered macroporous hydrogel as high performance catalyst," Materials Chemistry and Physics, 2014, 145, 418424.

51. Muhammad Imran Din and Aneela Rani., "Recent Advances in the Synthesis and Stabilization of Nickel and Nickel Oxide Nanoparticles: A Green Adeptness," International Journal of Analytical Chemistry, 2016, 2016, Article ID 3512145, 14.

52. Nadagouda, M.N. and Varma, R. S., "Green and controlled synthesis of gold and platinum nanomaterials using vitamin $\mathrm{B}_{2}$ : densityassisted self-assembly of nanospheres, wires and rods," Green Chemistry, 2006, 8(6), 516518.

53. Nagaraj, B., Krishnamurthy, N. B., Liny, P., Divya, T.K. and Dinesh, R., "Biosynthesis of gold nanoparticles of Ixora coccinea flower extract \& their antimicrobial activities," International Journal of Pharma and Bio Sciences, 2011, 2(4), 557-565.

54. Nowsath Rifaya, M., Theivasanthi, T. and Alagar, M., "Chemical Capping Synthesis of Nickel Oxide Nanoparticles and their Characterizations Studies," Nanoscience and Nanotechnology, 2012, 2(5), 134-138.

55. Palaniselvam Kuppusamy, Mashitah M , Yusoff, Gaanty Pragas Maniam, Natanamurugaraj, " Biosynthesis of metallic nanoparticls using plant derivatives and their new avenues in pharmacological applications- An updated report" Saudi Pharmaceutical Journal, 2016, 24(4), 473-484

56. Pandey, A. and Manivannan, R., "A Study on Synthesis of Nickel Nanoparticles Using Chemical Reduction Technique," Recent Patents on Nanomedicine, 2015, 5. 
57. Pandian, C. J., Palanivel, R. and Dhananasekaran, S. "Green synthesis of nickel nanoparticles using Ocimum sanctum and their application in dye and pollutant adsorption," Chinese Journal of Chemical Engineering, 2015, 23(8), 1307-1315.

58. Pang, H., Lu, Q., Li, Y. and Gao, F., Chem. Commun., 2009, 7542-7544.

59. Paskalis Sahaya Murphin Kumar1, Arul Prakash Francis2, Thiyagarajan Devasena3, "Comparative Studies on Green Synthesized and Chemically Synthesized Titanium Oxide Nanoparticles. A Validation for Green Synthesis Protocol using Hibiscus Flower," J. Environ. Nanotechnol. 2014, 3(4), 78-85.

60. Raj, K.J.A. and Viswanathan, B., "Synthesis of nickel nanoparticles with fcc and hcp crystal structures," Indian Journal of Chemistry, 2011, 50(2), 176-179.

61. Ratiram, G. C., Jay, A. T., Nilesh, V. G., Alok, R. R. and Harjeet, D. J., "Synthesis of nickel nanoparticles: Microscopic investigation, an efficient catalyst and effective antibacterial activity," Adv. Mater. Lett., 2015, 6 (11), 990998.

62. Raveendran, P., Fu, J. and Wallen, S.L., "A simple and green method for the synthesis of $\mathrm{Au}, \mathrm{Ag}$, and $\mathrm{Au}-\mathrm{Ag}$ alloy nanoparticles," Green Chemistry, 2006, 8(1), 34-38.

63. Ravikumar, S., Gokulakrishnan, R. and Boomi, P., "In vitro antibacterial activity of the metal oxide nanoparticles against urinary tract infectious bacterial pathogens," Asian Pacific Journal of Tropical Disease, 2012, 2(2), 8589.

64. Roselina, N.R.N. and Azizan, A., "Nickel nanoparticles: Study of particles formation and agglomeration," Procedia Engineering, 2012, 41, 1620.

65. Roya Nateghi, Gholam Reza Bonyadinejad1, Mohammad Mehdi Amin1, Hamed Mohammadi., "Decolorization of synthetic wastewaters by nickel oxide nanoparticle," International Journal of Environmental Health Engineering, 2012, 1 (3).

66. Roya, N., Gholam, R.B., Mohammad, M.A., Hamed, M., "Decolourization of synthetic wastewater by Nickel oxide nanoparticles," Int. J. Env. Health Eng., 2013, 1(1), 1-25.

67. Salvadori M R, C. A. O. Nascimento, and
B. Corrêa, "Nickel oxide nanoparticles film produced by dead biomass of filamentous fungus," Scientific Reports, 2014, 4, article 6404.

68. Sathyavathi S, A. Manjula, J. Rajendhran, and P. Gunasekaran, "Extracellular synthesis and characterization of nickel oxide nanoparticles from Microbacterium sp. MRS-1 towards bioremediation of nickel electroplating industrial effluent," Bioresource Technology, 2014, 165, 270-273.

69. Saxena A., A. Kumar, and S. Mozumdar, "Ni-nanoparticles: an efficient green catalyst for chemo-selective oxidative coupling of thiols," Journal of Molecular Catalysis A: Chemical, 2007, 269(1-2), 35-40.

70. Shakeel Ahmed, Mudasir Ahmad, Babu Lal Swami, Saiqa Ikram, "A review on plants extract mediated synthesis of silver nanoparticles for antimicrobial applications: A green expertise", Journal of Advanced Research, 2016, 7 (1), 17-28.

71. Singh R and V. Misra, "Stabilization of zerovalent iron nanoparticles: role of polymers and surfactants," in Handbook of Nanoparticles, 2015, 1-19.

72. Srivastava N.K., M.K. Jha and T.R. Sreekrishnan, "Removal of $\mathrm{Cr}$ (Vi) from Waste Water Using NiO Nanoparticles," International Journal of Science, Environment and Technology, 2014, 3(2), $395-402$.

73. Sudhasree, S., Shakila Banu, A. Brindha, P. and Kurian, G.A., "Synthesis of nickel nanoparticles by chemical and green route and their comparison in respect to biological effect and toxicity," Toxicological and Environmental Chemistry, 2014, 96(5), 743-754.

74. Sun, Y.P., X.-Q. Li, W.-X. Zhang, H.P. Wang, "A method for the preparation of stable dispersion of zero-valent iron nanoparticles," Colloids Surf. A., 2007, 308, 60-66.

75. Tao, D., Wei, F., "New procedure towards sizehomogeneous and well-dispersed nickel oxide nanoparticles of $30 \mathrm{~nm}$," Mater. Lett. 2004, 58(25), 3226-3228.

76. Thema, F. T., Manikandan, E., Gurib-Fakim, A. and Maaza, M., "Single phase Bunsenite NiO nanoparticles green synthesis by Agathosma betulina natural extract," Journal of Alloys and Compounds, 2016, 657, 655-661. 
77. Ullah M , A. Naz, T. Mahmood, M. Siddiq, and A. Bano, "Biochemical synthesis of nickel \& cobalt oxide nano-particles by using biomass waste," International Journal of Enhanced Research in Science Technology \& Engineering, 2014, 3, 415-422.

78. Uzaira Rafique1, Anum Imtiaz1, Abida K. Khan, "Synthesis, Characterization and Application of Nanomaterials for the Removal of Emerging Pollutants from Industrial Waste Water, Kinetics and Equilibrium Model," Journal of Water Sustainability, 2012, 2(4), 233-244.

79. Vaseem, M., Tripathy, N., Khang, G. and Hahn, Y.B., "Green chemistry of glucose-capped ferromagnetic hcp-nickel nanoparticles and their reduced toxicity," RSC Advances, 2013, 3(25), 9698-9704.

80. Vasudeo, K. and Pramod, K., "Biosynthesis of Nickel Nanoparticles Using Leaf Extract of Coriander," Biotechnol. Ind. J., 2016, 12(7), 106.

81. Vogel's Text Book of Quantitative Chemical Analysis, Editors: G. H. Jeffery J. Bassett J. Mendham R. C. Denney, Longman Scientific \&Technical, New York, 1989

82. Wang, C.B., Gau, G.Y., Gau, S.J., Tang, C.W. and Bi, J.L., "Preparation and characterization of nanosized nickel oxide, Catal. Lett., 2005, 101(3-4), 241-247.

83. Wang, Y. and Ke, J.J., "Preparation of nickel oxide powder by decomposition of basic nickel carbonate in microwave field with nickel oxide seed as a microwave absorbing additive," Mater. Res. Bull., 1996, 31(1), 55-
61.

84. Wang, Y. D., Ma, C.L. and Li, H.D., "Preparation of nanocrystalline metal oxide powders with the surfactant-mediated method," Inorg. Chem. Commun., 2002, 5(10), 751-755.

85. Wu, S. and Chen, D., "Syntheis and characterization of nickel nanoparticles by hydrazine reduction in ethylene glycol," Journal of Colloid Interface Science, 2003, 259, 282.

86. Wu, X., Xing, W., Zhang, L., Zhuo, S., Zhou, J., Wang, G. and Qiao. S., "Nickel Nanoparticles Prepared by Hydrazine Hydrate Reduction and Their Application in Supercapacitor," Powder Technology, 2012, 224, 162-167.

87. Xu, W., Liew, Y., Liu, H., Huang, T., Sun, C. and Zhao, Y., "Microwave assisted synthesis of nickel nanoparticles," Materials Letters,2008, 62, 2571.

88. Yuvakkumar, R., Suresh, J., Nathanael, A.J., Sundrarajan, M. and Hong, S. I., "Rambutan (Nephelium lappaceum L.) peel extract assisted biomimetic synthesis of nickel oxide nanocrystals," Materials Letters, 2014, 128, 170-174.

89. Zhang, X., Shi, W., Zhu, J., "Synthesis of porous $\mathrm{NiO}$ nanocrystals with controllable surface area and their application as supercapacitor electrodes," Nano Research, 2010, 3(9), 643-652.

90. Zhu, Z., Wei, N. Liu, H. and He, Z., "Microwaveassisted hydrothermal synthesis of $\mathrm{Ni}(\mathrm{OH}) 2$ architectures and their in situ thermal convention to NiO," Advanced Powder Technology, 2011, 22(3), 422-426. 